\title{
Evaluación de la adherencia a un tratamiento conductual para dejar de fumar: análisis de casos
}

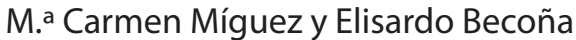 \\ Universidad de Santiago de Compostela
}

\section{RESUMEN}

En este estudio se analizan las dificultades que pueden presentar los fumadores que participan en un programa conductual de autoayuda para dejar de fumar y que pueden derivar en una falta de adherencia al tratamiento, que dificulte o impida la consecución de la abstinencia. A lo largo del tratamiento, para revisar la ejecución de las tareas y resolver las dudas y dificultades que pudieran surgir, a 100 fumadores que solicitaron dicho tratamiento se les realizó una llamada telefónica semanal durante las seis semanas que duró el mismo. Esto permitió realizar un análisis de contenido del proceso terapéutico. Mediante la trascripción del diálogo mantenido con dichos fumadores, se muestran las tareas que en ocasiones no se realizan, o se llevan a cabo incorrectamente, y la explicación de por qué sucede esto, con el objetivo de que todos aquellos profesionales que utilicen este tratamiento $u$ otros similares estén atentos a las mismas y sepan cómo resolverlas.

Palabras clave: Fumadores, tratamiento para dejar de fumar, adherencia, autoayuda, contacto telefónico.

\section{ABSTRACT}

In this study we analyse the problems or difficulties that may emerge for smokers participating in a self-help behavioural smoking cessation programme, and which can lead to lack of treatment compliance, which hinders or prevents the achievement of abstinence. Throughout the treatment, with a view to reviewing the performance of tasks and resolving the doubts and difficulties that may emerge, 100 smokers who participated in this treatment were telephoned weekly throughout the six weeks that the treatment lasted. This made it possible to carry out a content analysis of the therapeutic process. The transcription of the dialogue that took place with these smokers reveals the tasks which they sometimes failed to do, or did incorrectly, and permits an explanation of the reasons for these shortcomings, with the aim that all those professionals who use the above mentioned treatment are attentive to the same ones and they know how to solve them.

Keywords: Smokers, treatment for smoking cessation, adherence, self-help, telephonic contact. 
El tabaquismo sigue siendo la primera causa evitable de enfermedad y muerte prematura en los países desarrollados (WHO, 2008). Es, por tanto, un importante problema de salud pública. Por ello es necesario que exista un amplio abanico de procedimientos para ayudar a los fumadores que no logran dejar de fumar por sí mismos. Una de estas alternativas de tratamiento son las intervenciones psicológicas de autoayuda.

Las intervenciones en formato de autoayuda posibilitan el autotratamiento de diversos problemas (p. ej., ansiedad, depresión, consumo de sustancias). En el caso del tabaquismo, se trata de un procedimiento coste-efectivo que permite tratar a un amplio número de sujetos (Mains \& Scoging, 2003). Su finalidad es que el fumador abandone del tabaco por sí mismo (Lando, 1993; Lichtenstein, 1982; Schwartz, 1987; U.S.D.H.H.S., 1988). Desde su nacimiento, a finales de los años 60, principios de los 70, presentan su máximo apogeo en los años 80. En estos años proliferan los estudios al respecto, y empiezan a utilizarse distintas combinaciones y complementos a los materiales de autoayuda, con la finalidad de incrementar su efectividad. Actualmente, las nuevas tecnologías (p. ej., Internet, correo electrónico) aportan otra alternativa de tratamiento dentro de esta modalidad de intervención (Curry, Ludman \& McClure, 2003).

Para el tratamiento del tabaquismo, de todos los materiales de autoayuda existentes, el más utilizado es el manual o guía de autoayuda, que se encuadra dentro de la orientación terapéutica denominada biblioterapia. La mayoría de los manuales para dejar de fumar que se han evaluado son de base conductual y emplean tratamientos multicomponentes, pues la modificación de conducta lleva 40 años proporcionando tratamientos efectivos para los fumadores. Generalmente se trata de una adaptación de programas clínicos, de efectividad probada, a otros con formato autoadministrado (p. ej., American Lung Association, 1984, 1986; Becoña, 1993, 2007; Danaher \& Lichtenstein, 1978).

\section{Ventajas y limitaciones de la autoayuda}

Las intervenciones de autoayuda suponen importantes ventajas con respecto a las clínicas. Para los fumadores resultan más cómodas, pudiendo realizarlas en privado, y son más económicas, ya que suponen significativamente menos tiempo profesional y recursos que los implicados en tratamientos convencionales cara a cara. Para los profesionales, también resultan interesantes porque pueden aplicarse a un número elevado de fumadores a un coste relativamente bajo. Además, a nivel de salud pública pueden tener un gran impacto, debido a su posibilidad de distribución (Lancaster \& Stead 2009).

Asimismo, los tratamientos de autoayuda con manual tienen otras ventajas (Curry, 1993; Curry et al., 2003): 1) es posible distribuirlos a un bajo coste en una variedad de contextos; 2 ) se pueden elaborar para diferentes poblaciones (p. ej., basándose en el estadio de cambio o en características específicas de los fumadores); 3) los fumadores pueden adaptar el programa a sus necesidades específicas (p. ej., variar el orden en que se realicen los ejercicios recomendados, pueden seguirlo a su ritmo y 
terminarlo más tarde); 4) por la posibilidad de guardar los materiales escritos, los fumadores que fracasan en su intento de abandono del tabaco, pueden repetir con facilidad el programa (Glynn, Boyd \& Gruman, 1990) y, en caso de haber conseguido la abstinencia y experimentar momentos de tentación o consumos puntuales, podrían utilizarse para trabajar la motivación y reafirmarse en la decisión de mantenerse abstinente. Por consiguiente, se considera que favorecen el mantenimiento de los efectos del tratamiento (Glasgow, Schafer \& O'Neill, 1981).

Al igual que otros procedimientos de intervención, la utilización de tratamientos de autoayuda también tiene sus limitaciones o desventajas. Los manuales, por ejemplo, lo habitual es que hayan sido elaborados de forma sencilla, fáciles de aplicar y con posibilidad de adecuarse a cualquier persona y contexto. Este hecho, el que sean tan fácilmente aplicables, puede llegar a ser un inconveniente, puesto que deja la implantación del programa al arbitrio del sujeto, el cual ha de tomar decisiones en torno a las diversas cuestiones que surgen a lo largo del proceso de dejar de fumar, implicándole una mayor responsabilidad. Esto conlleva el riesgo de que el fumador no aplique el programa de tratamiento correctamente (Brown \& Owen, 1992).

Por otra parte, los métodos de autoayuda editados en formato de manual acostumbran a ser tratamientos estándar. Esto implica que no tienen en cuenta las peculiaridades de la conducta de fumar de cada persona (p. ej., su consumo de cigarrillos diario), ni permiten una adaptación del procedimiento al progreso que vaya obteniendo cada cual. Es, por tanto, el fumador el que tiene que adecuarlo a sus propias características y velocidad de ejecución de las tareas. Además, suelen estar dirigidos a aquellos fumadores que se encuentran en el estadio de cambio de preparados para la acción, y más del 50\% de los fumadores que solicitan estos tratamientos se hallan en estadios anteriores (Míguez, Vázquez \& Becoña, 2002). Incluso, en ocasiones, se solicita el tratamiento por curiosidad, pues suele tratarse de intervenciones gratuitas.

A pesar de las limitaciones comentadas, en los últimos años estas intervenciones han adquirido una gran relevancia como alternativa de tratamiento para los fumadores, sumándose a las mismas las realizadas a través de Internet (p. ej., Lenert et al., 2003).

Cabe destacar que cuando se utilizan sólo materiales de autoayuda, su eficacia suele ser inferior a la obtenida con programas clínicos (Míguez \& Becoña, 2003); debido, fundamentalmente, a la baja adherencia a las actividades del programa de intervención (Cummings, Emont, Jaen \& Sciandra, 1988; Davis, Faust \& Ordentlich, 1984; Glasgow et al., 1981; Míguez et al., 2000). Esto quiere decir que un porcentaje de los fumadores que solicitan estos materiales fracasan a la hora de completar algunas de las actividades recomendadas. Éste es también el principal problema que presentan los programas más novedosos, como los realizados por Internet, que son muchos los que los inician, pero pocos los que los llegan a finalizar (p. ej., Lenert el al., 2003). En relación a esta cuestión, diferentes estudios han comprobado que si se incluyen intervenciones comple- 
mentarias a los materiales de autoayuda, tales como llamadas telefónicas (p. ej., Brown, Hunt y Owen, 1992; Míguez \& Becoña, 2008; Míguez et al., 2002; Orleans, Schoenbach, Wagner et al., 1991), se favorece la ejecución de las tareas $y$, en consecuencia, mejoran los resultados.

Así pues, teniendo en cuenta que uno de los principales problemas de la utilización de materiales de autoayuda es la baja adherencia al tratamiento y esta falta de adherencia tiene repercusiones tanto clínicas como económicas, éste es un aspecto que debe preocupar a todos los profesionales. Además, no hay que olvidar que la adherencia es condición necesaria para poder comprobar que un tratamiento es efectivo. Si el análisis de los resultados de un tratamiento es importante, el análisis del proceso no lo es menos de cara a optimizar los resultados y entender qué es lo que promueve el cambio terapéutico. Por este motivo, en este estudio se ha realizado un análisis de contenido de las verbalizaciones de los fumadores mientras llevan a cabo un tratamiento de autoayuda, con la finalidad de que nos permita conocer de manera directa cómo se manifiesta la no adherencia al tratamiento, es decir, qué tareas, en ocasiones, no se realizan o se realizan incorrectamente y porqué. Se entiende que dicho análisis resultará de ayuda para todos aquellos profesionales que lleven a cabo esta intervención o cualquier otra que incluya alguno de los componentes que aquí se indican.

\section{Método}

El tratamiento de autoayuda que va a ser objeto de estudio es el programa conductual multicomponente Programa para Dejar de Fu- mar de Becoña (1993, 2007). Este es el tratamiento psicológico más utilizado en España para el abordaje del tabaquismo. Se trata de un procedimiento muy fácil de seguir que se encuentra totalmente protocolizado. En la modalidad de autoayuda, se envía el material por correo semanalmente al domicilio de los interesados en formato de manual de tratamiento de autoayuda o de folletos semanales. Los componentes que lo integran son los mismos que en el programa clínico, a excepción de que en este caso no se realizan mediciones de monóxido de carbono en cada sesión. Estos son los siguientes: 1) información sobre el tabaco; 2) autorregistros y representación gráfica del consumo de cigarrillos; 3) reducción gradual de la cantidad de nicotina y alquitrán, a razón de un 30\% semanal, mediante el cambio de marcas y la reducción gradual del número de cigarrillos; 4) control de estímulos; 5) estrategias para no padecer el síndrome de abstinencia de la nicotina; $y, 7$ ) estrategias para prevenir la recaída.

Los componentes anteriores se traducen en tareas a realizar a lo largo de las seis semanas que dura el tratamiento y que aparecen recogidas de forma resumida en la Tabla 1 (pp. 6-7). Las cuatro primeras semanas se orientan al abandono del tabaco, centrándose en la eliminación de las dependencias fisiológica, psicológica y social de los fumadores y, las dos últimas, se dedican a aspectos relacionados con la prevención de la recaída y el mantenimiento de la abstinencia.

La muestra objeto de este estudio, formada por 100 fumadores que realizaron el tratamiento de autoayuda para dejar de fumar por correo (62\% varones y $38 \%$ mujeres; 27,3 cigarri- 
Ilos/día de consumo pretratamiento), además de recibir cada semana el material de autoayuda con las tareas anteriormente comentadas, recibía una llamada por parte de un terapeuta al final de cada semana y a lo largo de todo el tratamiento (seis semanas), con el objetivo de revisar la realización de las tareas y resolver las dudas y dificultades que pudieran surgir, que en la intervención clínica se resuelven en las sesiones presenciales. Las seis Ilamadas efectuadas, previa autorización de los partícipes, se grabaron, lo cual permitió registrar y analizar las dudas y dificultades que iban surgiendo. De los 100 fumadores que se sometieron a tratamiento, 44 informaron acerca de alguna dificultad a la hora de adherirse a alguna de las tareas indicadas en el tratamiento. Puesto que en varios casos se trataba de la misma circunstancia, a modo de ejemplo aparece reflejada una trascripción de cada situación, en concreto se muestran 27 diálogos correspondientes a 25 fumadores.

\section{Resultados}

Se sabe que los participantes en una intervención de autoayuda pueden hallar algunas dificultades a la hora de seguir el tratamiento. Sin embargo, las investigaciones realizadas en torno a la evaluación de la adherencia de los programas para dejar de fumar se han centrado en la cuantificación del número de autoevaluaciones enviadas a lo largo del tratamiento (p. ej., Owen, Ewins \& Lee, 1989), y/o en evaluar el grado de lectura del material de autoayuda (p. ej., Brown, Hunt \& Owen, 1992). Aquí se ha pretendido hacer un análisis más exhaustivo de esta cuestión. Así, en el presente estudio, se intenta ilustrar de forma didáctica cómo manifiestan esta no adherencia los fumadores y que soluciones se les dan. Se trata de un análisis que complementa a un estudio publicado anteriormente (Míguez \& Becoña, 2005), en el que se constataban las dudas y/o dificultades que pueden presentar los fumadores en un tratamiento de estas características y el porcentaje, respecto a esta muestra, que presentaron estas dificultades. Aquí se realiza un análisis del contenido mediante la transcripción de las verbalizaciones de los participantes en el tratamiento. A continuación, se exponen los diálogos mantenidos con 25 fumadores que, en unos casos, informaban no haber realizado algunas tareas y, en otros, realizarlas de forma incorrecta.

\section{Comienzo del tratamiento}

La falta de adherencia se puede manifestar de diferentes formas. La mayor parte de las dificultades o problemas que pueden surgir en el proceso de abandono del tabaco con este procedimiento se detectan al principio del tratamiento. Al realizar la primera llamada, a finales de la primera semana, se comprobó que algunos fumadores no habían empezado el tratamiento. Las razones que se alegan para posponer el inicio del tratamiento son varias. De ellas, se exponen las dos más frecuentes:

1. Solicitan el tratamiento con la idea de empezarlo más adelante (p. ej., en vacaciones de verano cuando se encuentren más relajados).

Terapeuta: -Buenas tardes, J., llamo del Programa para Dejar de Fumar [1 1 llamada a un fumador que no había remitido el horario en el que debía indicar el día y la hora a la que quería ser llamado]. 


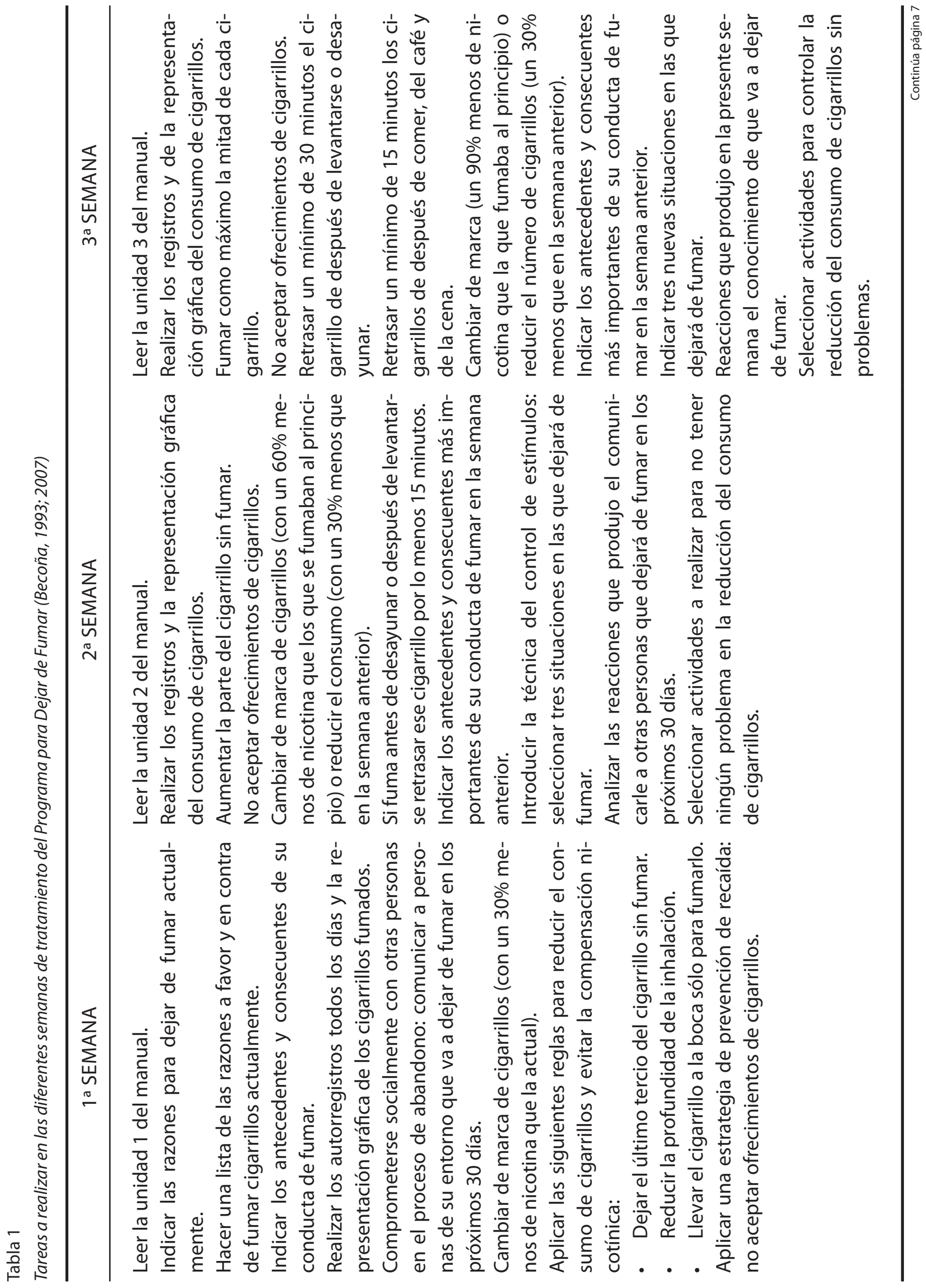




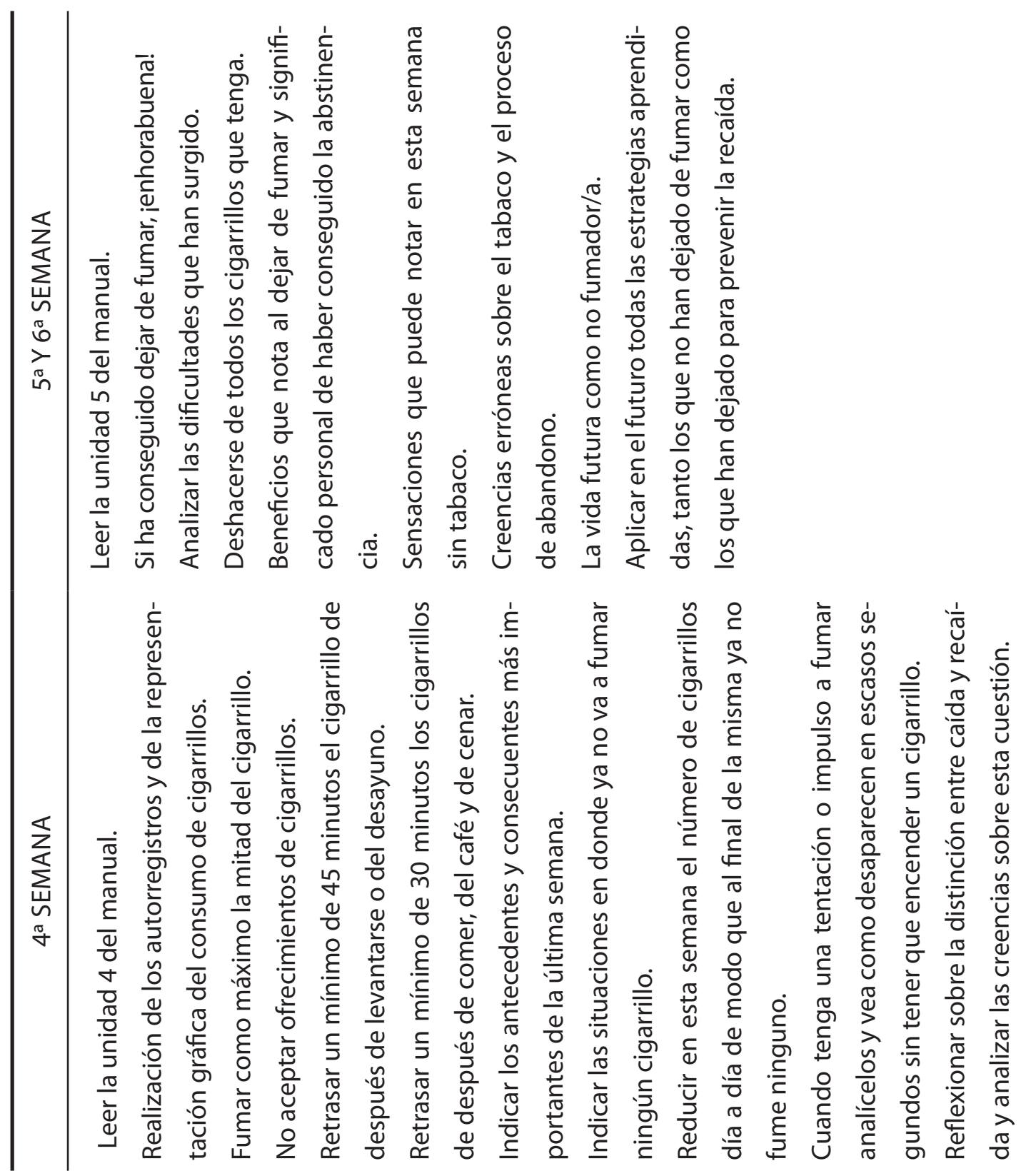


Sujeto: -Ah, sí, dígame.

Terapeuta: - ¿Ha recibido nuestras cartas?

Sujeto: -Sí, he recibido las primeras

Terapeuta:-Y, ¿ha leído la unidad 1 del manual?

Sujeto: -No

Terapeuta: ¿¿Está haciendo los autorregistros?

Sujeto: -No, tampoco

Terapeuta: - ¿Qué es lo que ha hecho hasta ahora?

Sujeto: -Yo es que esto lo quería iniciar en el verano, que es buena época, porque ahora viajo bastante [ 1 a semana de noviembre].

Terapeuta: - ¿A usted le viene bien que lo llame todos los lunes, a esta hora?

Sujeto: -Sí, no hay problema.

Terapeuta: -Bueno, pues si le parece, lo que podemos hacer es, al menos, intentarlo. Para ello, tiene que empezar leyendo la unidad 1 del manual, para poder empezar mañana con las tareas correspondientes a la primera semana (se le resumen las tareas para esta semana), y yo dentro de siete días lo vuelvo a llamar por si le ha surgido alguna duda.

Sujeto: -Bien, entiendo, empezamos por ahí; partiendo de la base.

Los fumadores deben enviar el horario (día/ hora) al que prefieren que se les llame. De esta forma, todas las semanas reciben la llamada el mismo día y hora. Como el tratamiento en este caso es gratuito, algunos lo solicitan con la finalidad de guardarlo y retomarlo en el futuro. Es importante que en esta primera llamada se den instrucciones concretas para comenzar de forma inmediata el tratamiento, pues al cabo de 7 días se les volverá a llamar. Se les hace ver que es una oportunidad única que se les brinda, pues van a recibir asistencia personalizada en su domicilio como si se tratase de un tratamiento clínico.

2. Se ausentan del domicilio durante un periodo de tiempo, habitualmente a consecuencia de un viaje. Al regresar, se encuentran con dos o tres cartas del programa y dicen no saber por dónde empezar, pues el tratamiento ha comenzado días atrás y ya llevan mucho retraso. Esto provoca que se agobien y decidan no realizar el tratamiento.

Terapeuta: -A., ¿ha recibido nuestras cartas? [1 ${ }^{\mathrm{a}}$ llamada a un fumador que no nos había remitido el horario].

Sujeto: -Sí, sí, pero es que tuve un problema y ya no empecé el tratamiento.

Terapeuta: -¿Quiere contarme qué le pasó?

Sujeto: -Bueno, pues, cuando recibí las primeras cartas, como faltaban dos semanas para terminar el mes, dije: "mejor empiezo el día 1 del próximo mes". Luego salí de viaje y, cuando llegué, ya había recibido el manual y la segunda semana de tratamiento. Entonces, ya no supe por donde empezar.

Terapeuta: -Entiendo. De todas formas, recuerde que cada siete días recibirá una carta

Sujeto: -Ya, ya, pero quiero decirle que no cubrí ningún papel ni hice nada.

Terapeuta: -Bueno, no se preocupe, lo primero es concretar el día y la hora a la que puedo llamarlo [se acuerda día y hora].

Sujeto: -Pero tendría que empezar ahora, porque no he hecho nada.

Terapeuta: -Sí, no importa. Hoy lea la unidad 1 de su manual y, mañana, empieza con las tareas correspondientes a esta unidad [se le resumen las tareas].

El fumador anterior es un ejemplo claro de un caso que se hubiera perdido de no realizar la llamada, pues se trataba de un fumador que consumía 30 cigarrillos diarios de la marca Ducados, que dejó de fumar al final del tratamiento y se mantuvo abstinente a lo largo de todos los seguimientos efectuados (3, 6 y 12 meses). Por lo tanto, una de las finalidades de la primera llamada es motivar y animar a los fumadores que todavía no han empezado el tratamiento a que comiencen de forma inmediata, pues aun- 
que lo hagan con una o dos semanas de retraso con respecto al resto de sus compañeros, es muy probable que dejen de fumar dentro de las seis semanas de duración del tratamiento, ya que la mayoría de los fumadores lo logran entre la tercera y cuarta semana.

\section{Los autorregistros}

La medida conductual más utilizada en el tratamiento de los fumadores son los autorregistros. Para que este instrumento tenga utilidad, hay que rellenarlo correctamente. En las hojas de autorregistro, que el fumador debe llevar en el paquete de tabaco, tiene que ir anotando cada cigarrillo que fume (en el momento en que lo va a encender o cuando lo esté fumando) y distintos aspectos de la conducta de fumar (hora de consumo, situaciones en las que fuma y placer que le proporciona evaluado cuantitativamente de 0 a 10). Deben realizarlos todos los días, desde una semana antes de empezar el tratamiento para establecer la línea base, y a lo largo de todo el tratamiento hasta que dejen de fumar. El autorregistro debe ofrecer información sobre los parámetros de la conducta de fumar, así como de las condiciones en que ocurre y las consecuencias que le siguen. La realización de los autorregistros es una de las principales tareas para el logro del autocontrol de la conducta de fumar con este tratamiento. Sin embargo, en ocasiones, se subestima la importancia de los mismos, pues a pesar de la información proporcionada en el manual de tratamiento, se interpreta que su único objetivo es cuantificar el número de cigarrillos que se fuman diariamente. Esto lleva a que no se realicen tal y como se indica en el programa de tratamiento. Por ello, consideramos muy importante que, siempre que se solicite al fumador información al respecto, no sólo se haga acerca de si realiza los autorregistros, sino también cuándo y cómo, y se insista en la importancia de los mismos en el supuesto de no estar realizándolos correctamente. Así, hemos detectado que son tres los principales problemas que suelen darse con la realización de los autorregistros: 1 ) que no lleguen a hacerlos; 2) que los cubran de forma irregular, no diariamente; $y, 3$ ) que los realicen de forma incorrecta (p. ej., al final del día).

El siguiente caso es de un fumador que no realizaba los autorregistros. Se le propone iniciarse en el hábito de los autorregistros paulatinamente.

Terapeuta: -¿Qué marca está fumando? (tercera semana de tratamiento)

Sujeto: -R1

Terapeuta: -¿R1 Ultra Light?

Sujeto: -Sí. Lo que pasa es que lo único que puedo hacer es ir bajando, y sin problemas con el R1, pero no he seguido en nada más el programa

Terapeuta: - ¿No ha leído el capítulo 1 ?

Sujeto: -Sólo lo he ojeado, y desde luego el tema de las hojitas para llevar en el paquete de tabaco y el registro diario de cigarrillos, no. Sé que he bajado de consumo, por el tabaco que compro.

Terapeuta: -Recuerde que los registros son una de las tareas fundamentales de este programa. $\mathrm{Si}$ no hace los registros, es más difícil que deje de fumar, pues le van a ayudar a conseguir el autocontrol de su conducta. Si en este momento le resulta difícil...

Sujeto: -Me resulta imposible. Sobre todo porque, en alguna situación, me es imposible quitar de papelito y escribir qué es lo que estoy pensando del cigarro que me estoy fumando.

Terapeuta:-Bueno, pues en un principio, intente apuntar sólo la hora. Esto ya le permitirá saber el 
número exacto de cigarrillos que fuma, cada cuanto tiempo los fuma y si fuma más por la mañana o por la tarde. Así es más fácil ¿no?

Sujeto: -Sí, algo más fácil es. Supongo que es cuestión de acostumbrarse. Parece una disculpa de mal pagador, lo que pasa es que no he tenido tiempo a sentarme más que a ojear los temas.

Terapeuta: -Bueno, ¿lo intentamos así esta semana?

Sujeto: -Venga, vamos a intentarlo

A continuación, se presenta una secuencia de la conversación mantenida con un fumador en el que se daban las situaciones 2 y 3 apuntadas anteriormente.

Terapeuta: -¿Y los registros?, ¿los está haciendo todos los días? (fumador que no había leído la unidad).

Sujeto: -Todos los días, todos los días, no. Es que muchas veces por motivos de trabajo, no puedo.

Terapeuta: -Pero, ¿no los lleva en la cajetilla?

Sujeto: -Sí, pero es que si está la máquina funcionando (en el trabajo) no puedo parar para apuntar.

Terapeuta: -Pero, para, a coger el cigarrillo.

Sujeto: -Eso es una cosa automática, lo tengo allí encima y lo cojo sin mirar.

Terapeuta: -De todas formas, es importante que tenga claro que cigarrillo y registro van unidos. En el registro debe apuntar como mínimo la hora y la situación. Así sabrá los cigarrillos que ha fumado a lo largo del día y...

Sujeto: -Sí, bueno, yo sé los que he fumado igual.

Terapeuta: -Sí, de acuerdo, pero los registros no sólo cumplen esa función. También le informan en qué situaciones fuma más y cuanto tiempo transcurre entre cigarrillo y cigarrillo. Por lo tanto, es fundamental que los cubra todos los días, ya que le van a ayudar mucho a controlar su consumo. Entonces, ¿la representación gráfica tampoco la hace?

Sujeto: -Sí, sí que la hago.

Terapeuta: -El problema es que si no tiene todos los registros no puede hacer bien la representación gráfica, pues le faltarán días.
Sujeto: -Pero, yo en casa, después, como sé los cigarrillos que fumo en toda la jornada, los apunto.

Terapeuta: -La cuestión es que para que el autorregistro cumpla su función, es necesario que los anote en el momento en que coja cada cigarrillo para fumarlo o cuando lo esté fumando. No como los está apuntando ahora. Así es como los autorregistros le ayudarán a fumar menos, pues será consciente de cada cigarrillo que fume y podrá comprobar el tiempo que ha transcurrido desde que fumó el último.

Sujeto: -Por supuesto que sí, porque eso implicaría tener que parar la máquina para fumarlo, o no la paro y no fumo.

Terapeuta: -Exactamente. Esa es una muy buena estrategia que puede utilizar.

Sujeto: -Bien, vale, lo voy a intentar así.

\section{Lectura del manual}

Si se hace referencia a un tratamiento de autoayuda, que se lleva a cabo siguiendo un manual, o folletos semanales, equivalentes a las unidades del manual, resulta obvio que la tarea básica a seguir sea la lectura de dicho material, pues si esto falla, fallará todo lo demás, pues, o no se realizarán las tareas, o se harán mal. Lo recomendable es dedicar de una a dos horas, el primer día de cada semana, a leer la unidad correspondiente a esa semana para, a continuación, iniciar las tareas asignadas. En este caso, hemos detectado que entre los que no se adhieren a la lectura del manual pueden darse las siguientes alternativas: 1) que no lo lean; 2) que lean sólo los resúmenes que figuran al final de cada unidad y, en consecuencia, no realicen las tareas correctamente pues se interpretan mal; 3) que lo ojeen (como ocurría con el caso comentado anteriormente que no hacía los registros); y, 4) que lo vayan leyendo poco a poco, en vez de leer cada unidad de un 
tirón. Esto último puede acarrear que no se realicen cada semana todas las tareas que correspondía hacer.

El caso que se expone a continuación no había leído la unidad correspondiente a esa semana.

Terapeuta: -¿Ha leído el capítulo 2 del libro? [al final de la segunda semana, después de informar que ha realizado sólo algunas tareas].

Sujeto: -No, todavía no.

Terapeuta: -Pues es necesario que lo lea. No es posible seguir el tratamiento sino se lee el libro. Además, ahora pronto tiene que empezar con la tercera unidad.

Sujeto: -Es que no tengo mucho tiempo.

Terapeuta: -Pero se trata de leer cada semana sólo una unidad, no todo el libro. Estamos hablando de sólo una hora de dedicación a la semana. Si no no podrá realizar las tareas. Además, al final de cada capítulo aparece un resumen de las tareas que debe hacer cada semana. Después de leer el capítulo, simplemente con ir a la página del resumen le será suficiente, pues ya recordará a que hace referencia cada tarea. Por ejemplo, el resumen de las tareas de la unidad 1 le viene en la página 40. Coja el libro, si no le importa.

Sujeto: -Sí, ya lo veo.

Terapeuta: -Bien, pues ahora en la página 57 le aparece el resumen de las tareas de la unidad 2, tareas que le correspondería hacer esta semana.

Sujeto: -Sí, sí, cambiar de marca... [lee alguna de las tareas].

\section{Cambio de marca de cigarrillos}

La dependencia fisiológica que provoca el consumo de tabaco, junto con la dependencia psicológica y social, es lo que dificulta o impide a un fumador dejar de fumar cuando se lo plantea. En la primera semana de tratamiento se introduce uno de los componentes que se utiliza en este programa para reducir la dependencia fisiológica. Se ha demostrado que los fumadores que dejan de fumar bruscamente sufren el síndrome de abstinencia de la nicotina. Sin embargo, reducciones semanales de un $30 \%$ en la cantidad de nicotina, respecto a la que ingerían con anterioridad, no produce problemas físicos, al tiempo que el fumador se habitúa a un nivel inferior de consumo si se le entrena para ello. Para conseguir esta reducción de un $30 \%$, a partir de la primera semana de tratamiento deberán cambiar a una marca de cigarrillos de menor contenido en nicotina que la que fumaban la semana anterior. Para ello, se proporciona información sobre los contenidos de nicotina y alquitrán de los cigarrillos de mayor consumo en España, y se indican los descensos que corresponde hacer de unas marcas a otras cada semana.

Respecto al cambio de marca, comprobamos que pueden darse diferentes circunstancias que conducen a que éste no se lleve a cabo o se realice mal. Cuando ello ocurre, los fumadores suelen hacer referencia a alguna de las siguientes situaciones:

1) Que no cambien de marca en la primera semana, porque anticipen que no se van habituar a una marca distinta de la que fuman cotidianamente. Esto ocurre, fundamentalmente, con los fumadores de Winston de contrabando (el de mayor contenido en nicotina) que nunca han fumado otro tabaco. Piensan que no les va a gustar o no se van a acostumbrar a otra marca distinta de la anterior, pues llevan muchos años fumando la misma. Lo importante en estos casos es explicarles que el cuerpo no entiende de marcas, lo que demanda es una dosis de nicotina. 
Terapeuta: - ¿Ha cambiado de marca? [primera llamada].

Sujeto: -No, es lo único que no he hecho. Lo demás lo he cumplido todo.

Terapeuta: -Pues debe cambiar de marca lo antes posible. Piense que usted fuma la marca de tabaco que mayor contenido tiene de nicotina.

Sujeto: -Sí, ya lo sé. Pero es que llevo 18 años fumando y siempre he fumado Winston.

Terapeuta: -Eso no importa. El cambio de marca sólo lo va a notar los dos o tres primeros días. Pronto se acostumbrará a la nueva marca. Además, puede seguir fumando Winston, pero nacional

...

Terapeuta: -¿Qué le ha parecido el Programa? [sexta llamada realizada al mismo fumador cuando lleva dos semanas sin fumar].

Sujeto: -Muy bien. Ahora me doy cuenta de que, a pesar de las dificultades que he tenido, no me ha costado el ir cambiando de marca. Yo creía que era totalmente imposible que no fumara Winston. Aún lo comentaba ahora con un compañero. A los dos nos ocurría que si nos ofrecían otra marca distinta a Winston no la queríamos.

2) En otros casos, a pesar de que se indica que cada semana hay que cambiar a una marca de menor contenido en nicotina, prolongan el consumo con una determinada marca, por no tirar el tabaco que han comprado.

Terapeuta: -¿Qué marca de cigarrillos está fumando ahora, R.?

Sujeto: -Hoy ya compré Fortuna Extra Light, pero empecé ahora el primer pitillo, porque como me quedaban unos cuantos y por no tirar la cajetilla ... [tendría que haber empezado tres días antes].

Terapeuta: -Bueno, pues debe cambiar de marca cada semana, aunque le sobren cigarrillos de la marca anterior.

Sujeto: - ¿Ah si?

Terapeuta: -Sí, al día siguiente de recibir el envío debe hacer lo que le viene en la unidad correspondiente a esa semana [se le explica que hay que dedicar una semana a los contenidos de cada unidad]. Piense que si no cambia de marca, no reduce la cantidad de nicotina que le corresponde respecto a la semana anterior.

3) Los que ojean el manual o leen sólo el resumen de las unidades, se quedan con la idea de que una tarea a realizar es "cambiar de marca de cigarrillos". Por lo tanto, cambian a una marca cualquiera (esto conlleva el riesgo de que cambien mal e incrementen la ingestión de nicotina, en lugar de disminuirla):

Terapeuta: - ¿Ha leído la unidad 1 de su manual?

Sujeto: -He leído un poco por encima, sí.

Terapeuta: -Bueno, pues es necesario que la lea entera. Y, ¿ha cambiado de marca?

Sujeto: -Sí, ya he cambiado de marca.

Terapeuta: -¿Qué marca está fumando?

Sujeto: -Ahora estoy fumando Royal Crown.

Terapeuta: - ¿Y qué marca fumaba antes?

Sujeto: -Lucky Strike.

Terapeuta: -Pero, ¿usted qué Royal Crown está fumando?, ¿el bajo en nicotina o el normal?

Sujeto: -El normal.

Terapeuta: - ¿El normal? Y antes me dice que fumaba Lucky Strike.

Sujeto: -Sí.

Terapeuta: -Entonces no ha hecho bien el cambio.

Sujeto: $-¿$ No?.

Terapeuta: -No, porque Lucky Strike tiene menos nicotina que Royal Crown, y hay que cambiar siempre a una marca con menor contenido de nicotina, no con mayor.

Sujeto: -¡Ajá!

Terapeuta: -Hay que ir descendiendo el nivel de nicotina. El Lucky Strike que usted estaba fumando tiene 1,0 mg. y el Royal Crown 1,2.

Sujeto: -Entonces aumenté, en vez de ir a menos.

Terapeuta: -Claro. Hay que pasar siempre a una marca menor. Cuando lea la unidad número 2, allí ya se le indica que tiene que volver a cambiar de marca. 
Sujeto: -¡Ajá! Es decir, todas las semanas cambiar de marca.

Terapeuta: -Exactamente. Si quiere seguir con Royal Crown, lo que puede hacer es fumar Royal Crown Light. ¿De acuerdo?

Sujeto: -Light, vale, vale.

Terapeuta: -Y esto a partir de mañana. Y si prefiere seguir con Lucky Strike también hay el Lucky Strike Light.

Sujeto: -Bueno, yo fue por cambiar de marca simplemente.

Terapeuta: -Pero es que no se trata de cambiar a cualquier marca. En la unidad 1 se le indica que hay que cambiar a una marca que tenga menor contenido de nicotina para ir perdiendo dependencia, y en la página ..., ¿qué manual tiene usted, en castellano o en gallego?

Sujeto: -Sí, en castellano.

Terapeuta: -Bueno, pues en la página 36 de su manual viene una tabla que le muestra cómo debe cambiar de marca.

Sujeto: -Pero ya le digo, solamente lo miré por encima, jeh!

Terapeuta: -Pues tiene que ir descendiendo cada semana en la cantidad de nicotina que tengan los cigarrillos, ¿comprende? Entonces J.A. a partir de mañana fumará Royal Crown o Lucky Strike, pero bajo en nicotina. Lo importante es que fume una marca con menos de 1,0 mg. de nicotina.

Sujeto: -Bien, ya cambio automáticamente. De acuerdo. Sí, sí, siempre a menos.

4) Cambian a una marca que les corresponde, pero no les gusta la nueva marca y vuelven a la anterior. Por ello, se debe explicar que lo importante no es la marca que se fume, sino su cantidad de nicotina. Es decir, si no gusta una marca en concreto, se elige cualquier otra con contenido similar. El siguiente caso es el de un fumador de Ducados que se pasó a Ducados bajo en nicotina. Como no se acaba de acostumbrar a esta marca, alternaba su consumo con Ducados.
Terapeuta: -¿Qué marca está fumando ahora X.?

Sujeto: -Ducados Light, pero ja ver si me voy acostumbrando a este tabaco!, porque claro, jcomo el Ducados normal es tan fuerte!, tengo que fumar de vez en cuando alguno.

Terapeuta: -Ah, hum.

Sujeto: -Este, parece que no da...

Terapeuta: - No se preocupe. Son los primeros días. Pronto se acostumbrará a la nueva marca. De todas formas, si sigue teniendo problemas puede probar con el BN o con el Coronas Light

Sujeto: -El Coronas Light es más suave, ¿no?

Terapeuta: -Sí, un poquito más, pero puede que le vaya mejor. Es decir, usted puede elegir entre el Ducados Light, el Coronas Light y el BN.

Sujeto: -Pues voy a probar con el Coronas Light, ja ver si me cae mejor al paladar!

Terapeuta: -Claro, o con el $B N$

Sujeto: -Es que el $B N$ también rasca bastante, prefiero probar con el Coronas, ja ver si me acostumbro mejor a él!, ¡como también es bastante suave!

Terapeuta: -Lo importante es que no fume una marca de cigarrillos superior a Ducados. Es decir, que tenga más nicotina, debe tener menos nicotina que la marca que estaba fumando.

Respecto a la marca, también puede ocurrir que cambien a una marca excesivamente baja y, por el proceso de compensación nicotínica, incrementen el consumo y/o den inhalaciones más profundas, para tratar de suplir la nicotina que dejan de ingerir con el cambio de marca. La compensación hace referencia a una modificación de la conducta de fumar, incrementando la intensidad o el número de las inhalaciones, debido a la alteración del nivel de nicotina en sangre (McMorrow \& Foxx, 1983, 1985).

5) Además, cuando pasan a fumar marcas con contenidos bajos en nicotina, hay que tener presente que éstas sólo se encuentran en 
estancos, no en máquinas expendedoras. Por ello, algunos fumadores tienen ciertas dificultades a la hora de encontrarlas y esto se usa como justificación para no cambiar de marca. En estos casos, debemos insistir en el hecho de que puesto que lo importante no es la marca que se fume, sino la cantidad de nicotina que contenga, si no se encuentra una marca en concreto, lo recomendable es comprar otra de igual o inferior cantidad y abastecerse para la semana.

Terapeuta: - ¿Qué marca está fumando? [llamada realizada en la segunda semana de tratamiento].

Sujeto: -Pues mire, sigo con Royal Crown, no, perdón, con Lucky, porque quise cambiar al Extra Light, pero no lo había. No lo consigo por ningún sitio.

Terapeuta: Pero tiene muchas marcas en donde elegir, ¿no?

Sujeto: -Sí, ya lo sé, ya lo sé. Lo que pasa es que como no lo conseguí, pues dije, pues voy a seguir fumando éste e intentar tirar menos del pitillo y así, por lo menos, hago el mismo sistema.

Terapeuta: -No. Es importante que cambie de marca.

Sujeto: - ¿Sí?

Terapeuta: -Sí, tiene que cambiar a una marca que tenga de nicotina un máximo de $0,7 \mathrm{mg}$. Es decir, pida una marca de $0,7,0,6$ o 0,4 . No le digo ninguna en concreto para que no tenga problemas en encontrarla, icomprende?

Sujeto: -Ya

Terapeuta: -Porque si le digo que se compre, por ejemplo, el Gold Coast Ultra Light, que tiene 0,6, puede ocurrir que en el estanco al que usted va habitualmente no tengan esta marca.

Sujeto: -O sea, que tiene que tener 0,6 .

Terapeuta: -Lo ideal es que esta semana fume una marca de 0,6, pero no importa si tiene 0,7 ó 0,4. Lo importante es no pasarse de 0,7 y empezar mañana con la nueva marca.

Sujeto: -Vale.

\section{Aumentar la parte no fumada de cada cigarrillo}

En la primera semana de tratamiento, para ayudar a ir perdiendo dependencia fisiológica a la nicotina, se indica que se debe aumentar la parte no fumada de cada cigarrillo. Es decir, si el fumador solía fumar el cigarrillo hasta el filtro, debe pasar a dejar un tercio sin fumar. $\mathrm{Si}$ ya dejaba un tercio, pasará a dejar la mitad. La razón de esta regla es que el cambio de marca puede llevar al fumador a efectuar el proceso de compensación, consistente en este caso en reducir la nicotina por un lado (con el cambio de marca) y aumentarla por otro, fumando más. Además, el último tercio del cigarrillo, el próximo al filtro, contiene tanta cantidad de nicotina, alquitrán y otros componentes del tabaco, como los otros dos tercios. Con esta regla se evita la compensación nicotínica, por ello, cada semana se aumentará la parte no fumada de cada cigarrillo.

Puesto que algunos fumadores alegan que se olvidan de apagar los cigarrillos antes de llegar al filtro, en estos casos, se recomienda marcar todos los cigarrillos para recordar por donde hay que apagarlos.

Terapeuta: $-Y$, ¿deja un tercio sin fumar? [llamada realizada en la segunda semana de tratamiento].

Sujeto: -Bueno, lo intento, pero eso me cuesta.

Terapeuta: -Le cuesta, pero tiene que intentar acostumbrarse. Piense que esta semana ya tenía que dejar la mitad del cigarrillo sin fumar.

Sujeto: -Sí, es quizás lo que más me cuesta. Lo que ocurre es que como tengo un trabajo muy manual, muchos se consumen en el cenicero, por tanto, ese tercio ya no lo fumo.

Terapeuta: -Pero no se trata de dejar un tercio cualquiera, sino el último tercio del cigarrillo, el próximo al filtro. 
Sujeto: -Entiendo.

Terapeuta: -En él se acumulan la mayor parte de las sustancias nocivas. Lo que le puede ayudar, es poner una marca a todos los cigarrillos, y cuando llegue a ella, los apaga. La marca será su nuevo filtro. Así le resultará más fácil.

Sujeto:-Bueno, pues intentaré hacerlo así a partir de ahora.

\section{Retrasar el cigarrillo de después de le- vantarse o desayunar, de las comidas y del café}

Para contribuir al descenso de la dependencia de los cigarrillos, en la segunda semana de tratamiento se introduce una nueva tarea. Si el fumador fumaba antes de desayunar o inmediatamente después de levantarse, debe retrasar ese primer cigarrillo de la mañana un mínimo de 15 minutos. A partir de aquí, cada semana se retrasará cada vez más el primer cigarrillo que se fume después de cada comida y con el café. Se trata de distanciar dos conductas muy ligadas (café-cigarrillo, comer-cigarrillo), para ir perdiendo, poco a poco, la asociación que hay establecida entre ambas. Algunos fumadores afirman no ser capaces de esperar dicho tiempo. En ese caso, resulta útil ayudarles a redistribuir las actividades que realizan, de manera que transcurra el tiempo necesario hasta que puedan fumar.

Terapeuta: -Por la mañana, ¿espera siempre 15 minutos después de desayunar para fumarse el primer pitillo? [llamada realizada en la segunda semana].

Sujeto: -Pues eso es lo que no soy capaz aún. Por la mañana, después de desayunar, cojo el coche para ir al trabajo y enciendo el pitillo. Me cuesta. Por la mañana es cuando más me cuesta.

Terapeuta: -Ya sabe que hay que intentar espe- rar un mínimo de 15 minutos. Vamos a ver, usted se levanta, y una vez que desayuna dice que...

Sujeto: -Sí, cojo el coche.

Terapeuta: -Y que fuma, ¿en el coche?

Sujeto: -Sí, sí, sí, siempre.

Terapeuta: -Entonces sería conveniente que esa situación la eliminara. Es decir, de las tres situaciones que debe elegir cada semana, en las que se va a prohibir fumar, sería conveniente que eligiera la de fumar en el coche [tarea que se explica en el próximo apartado]. ¿Cuánto tiempo le lleva el trayecto hasta el trabajo?

Sujeto: -Poco, poco, 10 minutos.

Terapeuta: -Bien, pues piense que si se prohíbe fumar en el coche ya se obliga a esperar un mínimo de 15 minutos después de desayunar.

Sujeto: -Sí, podría ser. Lo fumo al llegar al despacho, por ejemplo.

Terapeuta: -Exactamente. Entonces, si le parece, vamos a intentar hacer esto para esta semana.

Sujeto: -De acuerdo.

\section{Control de estímulos}

Para reducir la dependencia psicológica o conductual que crea el tabaco, en la segunda semana de tratamiento se introduce el control de estímulos sobre la conducta de fumar. El objetivo de esta técnica es conseguir reducir el número de señales asociadas con fumar antes de que el fumador consiga la abstinencia. Para ello, se pide a los fumadores que indiquen cuáles son los antecedentes y consecuentes de su conducta de fumar, mediante el análisis de los registros realizados a lo largo de la primera semana de tratamiento. Dado que se fuma en situaciones concretas, a partir de este momento se va a ir restringiendo el consumo de cigarrillos en algunas de ellas, empezando siempre por aquéllas de más fácil logro. Cada 
semana se irán incrementando tres nuevas situaciones en las que no se podrá fumar. Es importante hacer hincapié en que se debe elegir situaciones en las que acostumbran a fumar, empezando siempre por las más sencillas de cumplir. En este caso, pueden darse diferentes circunstancias:

1) Que hagan la "trampa" de elegir situaciones en las que no fuman, a pesar de que en la unidad 2 del manual se especifica que del listado de situaciones que se proporciona se tachen aquéllas en las que nunca fuman $y, a$ continuación, se seleccionen tres en las que, a partir del día siguiente, no se fumará ningún cigarrillo. El siguiente ejemplo es el de una fumadora que aparentemente ha cumplido esta tarea pero en realidad de las tres situaciones sólo ha elegido una.

Terapeuta: -Esta semana, ¿ha elegido tres nuevas situaciones, respecto a la semana anterior, en las que no va a fumar? [llamada realizada en la tercera semana de tratamiento].

Sujeto: -Sí.

Terapeuta:-¿Cuáles son?

Sujeto: -Puesss..., viendo la televisión, porque total apenas fumaba antes, pero bueno, por si acaso algún día, escribiendo a ordenador, y paseando, que también es raro que fume.

Terapeuta: -Bueno, recuerde que para la próxima semana deberá elegir tres nuevas situaciones en las que fume habitualmente.

2) Que en lugar de empezar por las situaciones más fáciles de cumplir, elijan situaciones «difíciles», en las que fuman a diario. Esto puede llevarles a no ser capaz de cumplirlas.

3) Además, al final del tratamiento, se introduce el control de estímulos como prevención de la recaída, a través de la eliminación de todos los cigarrillos que tengan en casa, coche o cualquier otro sitio donde los guarden habitualmente. En este caso, algunos fumadores se resisten a quedarse sin tabaco, una vez que han dejado de fumar o la semana que tienen que dejarlo, por miedo a que les surja la necesidad de fumar. Esto puede dificultar la consecución de la abstinencia o precipitar una recaída.

Terapeuta: -M., ¿tiró todos los cigarrillos que le quedaban? [fumadora que tenía que haber dejado de fumar esta semana. El día que se había acordado para que dejara de fumar, a las 9 de la noche fumó un cigarrillo].

Sujeto: -No, no, eso no.

Terapeuta: -¿Cómo no?

Sujeto: -Es que yo quiero dejar de fumar con tabaco. Yo quiero dejar de fumar y dejar en el bolso un cigarrillo y en el trabajo otro cigarrillo.

Terapeuta: -M., eso, precisamente, no le va a ayudar a dejar de fumar.

Sujeto: -Sí, ¿sabe por qué?, porque, si tengo un momento de angustia, me fumo un cigarrillo.

Terapeuta: -Pero eso no lo debe hacer. Una vez que deje de fumar, no puede andar probando de vez en cuando, pues eso le llevará a la recaída.

Sujeto: -Sí, eso lo leí. También leí que si fumas uno no pasa nada, el caso es no volver a fumar como antes.

Terapeuta: -Pero eso no es tan fácil. Si estas son sus expectativas, lo más probable es que no deje de fumar. Piense que al dejar de fumar, si en un determinado momento siente ganas de fumar y tiene tabaco a mano, es muy probable que lo fume. Si no lo tiene, esas ganas le remitirán en cuestión de unos segundos y seguirá abstinente. Es una pena que esté prolongando esta situación, pues con trescuatro cigarrillos que está fumando al día y además por la mitad ya no tiene dependencia fisiológica; por tanto, no lo va a pasar mal al dejarlos.

Sujeto: -Sí, eso ya lo sé. Vale, pues voy a intentarlo.

Hasta aquí se han comentado dificultades que pueden surgir en relación a tareas con- 
cretas que se indican en el programa de intervención al que hemos hecho referencia, todas ellas relacionadas con la falta de adherencia al tratamiento. Además de las dificultades comentadas, también hay otros aspectos que, de darse, pueden influir negativamente en la consecución de la abstinencia. A continuación se comentan los más frecuentes.

\section{Ausencia de apoyo social}

El apoyo social facilita o favorece el abandono del tabaco, así como superar momentos difíciles que se puedan presentar a lo largo del tratamiento. Por ello, desde el comienzo del tratamiento, ya en la primera semana, el fumador debe adoptar y mantener un papel activo y público en el proceso de dejar de fumar. Para esto es importante que se comprometa con las personas que le rodean (familiares, amigos, compañeros de trabajo...) y les comunique que va a dejar de fumar en el plazo de un mes. Esto facilitará la implicación activa del sujeto en el cambio de su conducta y el poder analizar tanto las reacciones de esas personas como las suyas, ante el hecho de dejar de fumar. En sucesivas semanas de tratamiento, se comentan las reacciones que percibe el fumador de los demás, acerca del apoyo o no, a su abandono del tabaco. Lo esperable y deseable en estos casos es que reciba el máximo apoyo por parte de las personas que le rodean, pero, desafortunadamente, no siempre es así $y$, a veces, el fumador no encuentra apoyo en todo el proceso de abandono del tabaco. Esta falta de apoyo varía según proceda de fumadores, no fumadores o fumadores que han intentado dejar de fumar y se puede manifestar de varias formas. Las más habituales son: 1) Otros fumadores que, con su conducta, dan la impresión que desean que no consiga dejar de fumar, con argumentos del tipo: que el programa no le va a funcionar o que no lo va a lograr porque ellos también lo intentaron y fracasaron. Si esto no ocurre, es decir, si a pesar de sus profecías logra dejar de fumar, pasan a la siguiente fase, que consiste en predecir su recaída, primero a corto, luego a medio $y$, finalmente, a largo plazo. 2) Otros, le recuerdan al fumador, de forma insistente: «decías que ibas a dejar de fumar y sigues fumando». Por ello, para evitar lo anterior, es importante recalcarle al fumador que, cuando comunique a las personas que le rodean que va a dejar de fumar, les aclare que esto va a ser en el plazo de un mes, puesto que hay que comprender que si no se conoce el procedimiento, puede resultar un poco extraño el hecho de seguir fumando si se está realizando un tratamiento para dejar de fumar.

Terapeuta: - ¿Cuál ha sido la reacción de los que le rodean al comunicarles que iba a dejar de fumar?

Sujeto: -Mi mujer encantada, pero los demás cuando me ven encender un cigarrillo, a veces me dicen: ¿pero no estás dejando de fumar? Yo creo que no se lo creen.

Terapeuta: $-i Y$ les ha explicado que se trata de un proceso gradual y que dejará de fumar en el plazo de un mes?

Sujeto: -No, paso de explicarles.

3) Por último, están los escépticos, que sólo creen lo que ven, y dicen «eso ya lo has dicho muchas veces. Me lo vas a tener que demostrar». Esto último, fue lo que le ocurrió al siguiente fumador.

Terapeuta: - ¿Ha comunicado a los que le rodean que iba a dejar de fumar? 
Sujeto: -Sí, por supuesto.

Terapeuta: -¿Y qué tal?

Sujeto: -Pues, bueno, me animan, aunque no se lo creen mucho, porque ya no es la primera vez que les digo que lo voy a dejar, y en fin, no...

Terapeuta: -Bueno, pero algún día tiene que ser, ¿verdad?

Sujeto: -Sí, por su puesto, yo espero que sea de esta vez. Pero es que lo he dicho tantas veces que para que me crean voy a tener que demostrárselo.

\section{Mejoría física}

En torno a la tercera semana de tratamiento es habitual que se empiece a notar mejoría física: menor cansancio al caminar o subir escaleras, mayor resistencia si se hace deporte, mejor respiración, mayor percepción de olores y sabores, etc. Sin embargo, al mismo tiempo, la reducción de la dependencia del tabaco lleva consigo toda una serie de síntomas tales como carraspera, catarro, aumento de las secreciones mucosas, sensaciones molestas en la garganta, etc., que pueden parecer contradictorias a esa mejoría física que se ha empezado a experimentar. Estas sensaciones hay que interpretarlas como un síntoma positivo, como una señal de que el organismo comienza a recuperarse y ha empezado el proceso de "limpieza" de los pulmones. En cuanto a las molestias que pueden notar en la garganta, se deben a que se empiezan a percibir las sensaciones del aparato respiratorio, tal y como son realmente, pues el tabaco tenía amortiguadas todas estas sensaciones. Si esto no se tiene presente $y$, en el caso de este tratamiento de autoayuda, no se lee detenidamente la unidad 3 del manual en la que se explica, puede llevar a que el fumador crea que está empeorando, en vez de mejorar, y comente que se encuentra fatal, está muy atascado/a, le duele la garganta y antes nunca le dolía, etc. Esto, en algunos casos, se puede llegar a utilizar como disculpa para volver a fumar.

Sujeto: - ¡Ah!, le iba a preguntar una cosa.

Terapeuta: -Dígame.

Sujeto: -Es que me encuentro mal, me duele la cabeza, la garganta y tengo bastante mal el intestino. O sea, no se si tiene que ver, pero vaya, desde que dejé de fumar estoy un poco descontrolada.

Terapeuta: -Descontrolada ¿en qué sentido?

Sujeto: -[Pregunta si tiene que ver con el hecho de dejar el tabaco el que ahora tenga molestias de garganta y el que esté estreñida, porque nunca había tenido problemas. Se le aclara que le puede haber influido en cierta medida y que debe compensarlo con una alimentación adecuada, rica en fibra].

Sujeto: $-Y$ engordar, engordé dos kilos, pero bueno.

Terapeuta: -Eso es habitual, en el libro ya se le indica que los fumadores pesan, por término medio, de dos a tres kilos menos con respecto a los no fumadores. En cuanto a las molestias que tiene en la garganta, es normal y positivo que esto le ocurra, pues se debe a que empieza a percibir las sensaciones que, antes con el tabaco, tenía atrofiadas.

Sujeto: -jAh!, bueno.

\section{Estancamiento en el consumo}

Hacia el final del tratamiento, en torno a la cuarta semana, a veces se produce un estancamiento en el consumo. Esta circunstancia se suele dar en dos tipos de fumadores:

1) Aquellos que desde el principio del tratamiento no han sido capaces de reducir el consumo tal y como se indicaba para cada semana y se estancan en un consumo elevado, del 
orden de los 15 cigarrillos. En este caso, si las estrategias que permiten reducir no han funcionado, puede resultar útil plantearse dejarlo bruscamente, pues es una opción que prefieren algunos fumadores.

Terapeuta: -¿Qué tal esta semana? [llamada realizada en la cuarta semana].

Sujeto: -Bueno, regular.

Terapeuta: ¿¿Cómo es eso?

Sujeto: -Regular, porque ya es la cuarta semana y debería de estar sin fumar nada y todavía estoy así.

Terapeuta: ¿QQué marca está fumando?

Sujeto: -Estoy fumando R1. El problema es que bajo poco, pocos pitillos $y$, aunque me lo propongo, no lo logro. Me es imposible, sobre todo en el trabajo [se comprueba que ha realizado correctamente todas las tareas, exceptuando la reducción en el número de cigarrillos].

Terapeuta:-¿Cuánto ha fumado esta semana?

Sujeto: -Sigo igual, 14, 15. Dos días logré fumar 10, 11, pero nada más.

Terapeuta: -Bueno, el hecho de que lleve dos semanas fumando más o menos lo mismo, y que tenga tantas dificultades para bajar de este consumo, nos puede estar indicando algo, y es que llegó su hora. Es decir, debe plantearse dejar de fumar.

Sujeto: -La verdad es que es algo que se me pasó por la cabeza porque me di cuenta de que la nicotina ya no manda en mí como antes.

Terapeuta:-Cuando se produce un estancamiento en el consumo y, además, como en su caso, se está fumando la mitad del cigarrillo, de una marca tan baja en nicotina, algunos fumadores prefieren plantearse dejar de fumar y no estar pendientes de esos cigarrillos. De todas formas, de cara a la próxima semana, podemos plantearnos esto o fijar un consumo máximo de 10 cigarrillos. Esto lo consigue eliminando tres nuevas situaciones y tratando de alargar el tiempo entre cigarrillos, con la ayuda de los autorregistros. Tiene las dos alternativas. La elección es suya.
Sujeto: -Sí, a veces me da la impresión de que me paso la tarde tratando de repartir los cigarrillos y preocupada por los que ya he fumado.

Terapeuta: -Bueno, pues si decide dejar de fumar, como yo le llamo el martes, lo ideal sería que lo dejara el sábado o domingo, para que lleve un par de días sin fumar y me pueda contar cómo lo lleva.

Sujeto: -Me parece un poco difícil, pero voy a intentarlo, porque quizás me agobie más el no poder pasarme de 10.

Terapeuta: -Puede intentar durante un par de días limitar su consumo a un máximo de 10 cigarrillos, y si no lo consigue, intente dejarlo.

Sujeto: -De acuerdo.

2) Por otra parte, están los que evolucionan muy bien a lo largo del tratamiento y llegada la tercera o cuarta semana se encuentran fumando de 3 a 5 cigarrillos, aproximadamente. En este caso, el siguiente paso sería dejar de fumar, pues están preparados para ello. Sin embargo, en ocasiones, nos encontramos con fumadores que informan llevar en torno a dos semanas fumando alrededor de 5 cigarrillos y no se deciden a dejarlo definitivamente. Esta es una situación que entraña cierto peligro, pues si se sigue prolongando hemos comprobado que cambia su objetivo con respecto al tratamiento y empiezan a crearse la ilusión de quedarse así, con un consumo mínimo. En consecuencia, siguen teniendo tabaco consigo. El siguiente caso es un ejemplo de esto.

Terapeuta: -Hola. Buenas tardes. ¿Qué tal lo lleva J.?

Sujeto: -Bueno, mal, jeh!

Terapeuta: -¿Cómo mal?

Sujeto: -Sí, sí.

Terapeuta: -Cómo es eso, explíqueme...

Sujeto: -Porque de vez en cuando fumo un cigarro, jeh! 
Terapeuta: -Usted, ¿qué día había dejado de fumar?, ¿el 18, cómo habíamos acordado?.

Sujeto: -Lunes, sí.

Terapeuta: -¡Ajá!. Pues cuénteme un poquito. El lunes 18 , ¿no fumó nada?

Sujeto: -No.

Terapeuta: - ¿En todo el día?

Sujeto: -Exacto.

Terapeuta: - ¿Y el domingo cuánto había fumado?.

Sujeto: - ¿El domingo? El domingo cinco.

Terapeuta: - ¿El martes?.

Sujeto: -El martes dos.

Terapeuta: - ¿Y eso cómo fue?, se los ofrecieron, los cogió...¿qué pasó?

Sujeto: -No, no, de los que tengo yo.

Terapeuta: -Pero, ¿no ha tirado el tabaco?

Sujeto: -No.

Terapeuta: - ¿Y eso? Usted ahora no tiene que comprar más tabaco y, además, debe tirar todo el que tiene.

Sujeto: -Sí, sí, ya.

Terapeuta: -Sabe que en la unidad 5 de su manual, se le indica que debe deshacerse de todo el tabaco que tenga a mano. Así le será más fácil no fumar, ¿comprende? Si usted no tuviese tabaco, esos dos cigarrillos es posible que no los hubiese fumado.

Sujeto: -No, posiblemente.

Terapeuta: -Por eso es importante que no tenga tabaco consigo. Ayer, miércoles, ¿cuánto fumó?

Sujeto: -Ayer, también dos.

Terapeuta: -Bueno, pues tiene que dejarlo, ¿sabe? Usted lo llevaba muy bien. Llevaba casi dos semanas fumando 5 cigarrillos y resulta muy peligroso estar fumando esos dos cigarrillos, porque aunque ahora son sólo dos, si continúa así, dentro de un mes puede estar fumando 25 , como cuando empezó el tratamiento. Y ¿hoy ha fumado?

Sujeto: -Sí.

Terapeuta: -¿Cuántos?

Sujeto: -Llevo tres. Aumenté.
Terapeuta: -Y mañana es posible que sean $4, y$ así sucesivamente, pues es un proceso gradual y cada vez necesitará más "dosis" de nicotina.

Sujeto: -Entonces lo que tengo que hacer es no tener tabaco, no comprarlo.

Terapeuta: -Comprarlo bajo ningún concepto. Tiene que pensar que una persona no fumadora no necesita tabaco pero, además, debe tirar los cigarrillos que tiene, pues le ayudará a no fumar.

Sujeto: -De acuerdo, pues lo voy hacer.

\section{Momentos de desánimo}

En el proceso de dejar de fumar la motivación puede fluctuar, los fumadores pueden pasar por momentos de desánimo, debido a un retroceso, a que se va más lento de lo previsto o, simplemente, a que se sienten desmotivados o incapaces de dejarlo, les cuesta seguir adelante y empiezan a pensar que no lo van a lograr. Esta circunstancia, en ocasiones, puede conducir al abandono del programa; por ello, es importante hacer mención a que esto puede ocurrir, pero que suele ser algo puntual y no debe ser utilizado para "tirar la toalla". La siguiente es una llamada realizada, en la segunda semana de tratamiento, a una fumadora que había progresado mucho en dos semanas. Ahora, comenzaba a dudar de sus posibilidades porque tenía mucha urgencia en dejar de fumar.

Sujeto: -... prácticamente ya no trago casi nada el humo.

Terapeuta: -Ya no traga el humo. Muy bien, pues eso le va a ayudar.

Sujeto: -Que es bastante difícil ¡eh!, pero bueno, a ver si tengo suerte y sigo adelante. A veces, claro, está uno un poco como dudando de si será capaz de conseguirlo; como un pequeño rechazo hacia el tratamiento; pero pienso que es normal. 
Terapeuta: -Durante el proceso de dejar de fumar puede haber momentos de duda, como usted dice, sobre todo teniendo en cuenta que usted nunca había dejado de fumar con anterioridad. Lo importante, en este caso, es que tenga claro que lo que quiere es dejar de fumar y que no se desmotive ante la mínima adversidad. Simplemente céntrese en las tareas que se le proponen para cada semana. No se marque metas demasiado elevadas que no pueda conseguir, porque todavía no es el momento, y que le podrán llevar al desánimo. Además, hasta ahora, lo lleva muy bien. Tiene que pensar que estamos en la segunda semana y que todavía quedan cuatro semanas de tratamiento.

Sujeto: -No, ya lo sé.

Terapeuta: -Y pronto dejará de fumar.

Sujeto: -Eso espero, pero es que a veces de verdad uno se siente a flaquear un poco.

Terapeuta: -Si sigue los pequeños pasos que se le indican semana a semana verá que lo deja casi sin darse cuenta.

Sujeto: -Ya, yo pienso que es normal, vaya, esa impresión que tengo de no ser capaz.

Terapeuta: -No se preocupe, el próximo lunes, cuando le llame, ya habrá superado todo eso y estará a punto de dejar de fumar.

Sujeto: -Bueno, pues, ja ver si es verdad! y muchas gracias.

Terapeuta: -Hola A.M. Buenas tardes. Llamo del PDF [primera llamada].

Sujeto: -Hola. No envié nada, porque verá, empecé a hacerlo pero no fui capaz.

Terapeuta: -¿Qué es lo que no fue capaz?

Sujeto: -Pues eso, de hacerlo.

Terapeuta: -Bueno, primero dígame qué día y a que hora le va bien que la llame.

Sujeto: -Pues por ejemplo hoy, martes, a partir de las 7. Pero es que mire una cosa

Terapeuta: -Dígame.

Sujeto: -Como no lo hice, ¿entiende?. Lo hice tres días y después, no sé, no fui capaz. Y una vez que lo dejas un día, después volver a retomarlo...

Terapeuta: -Bueno, por eso no se preocupe. Vamos a olvidar lo que pasó y vamos a intentarlo de nuevo, ¿le parece?

Sujeto: -Sí.

Terapeuta: -Usted, ¿qué es lo que había hecho del programa? ¿Había hecho los autorregistros de la línea base?

Sujeto: -Sí, empecé a hacerlos, pero a las dos de la tarde vi que ya llevaba 13 pitillos y pensé "bueno, esto es de locos". Entonces, me desanimé de una forma tan grande que no se puede dar idea. Y aparte, como estoy pasando una época un poco baja dije: "no soy capaz, no soy capaz".

Terapeuta: -Sí es capaz. Al menos, vamos a intentarlo, ¿de acuerdo?

Sujeto: -Me gustaría mucho poder conseguirlo.

Terapeuta: -Bueno, pues para poder conseguirlo, primero hay que intentarlo. Además, la voy a llamar todas las semanas, y eso la va a ayudar [se le explica la importancia de los autorregistros y se resumen las tareas que deberá hacer a partir del día siguiente].

Los retrocesos y/o incrementos en el consumo de cigarrillos pueden venir dados por tratar de dejar de fumar antes de lo previsto y de lo recomendado, pues no se está preparado para ello, y esto puede derivar en el desarrollo de síntomas propios del síndrome de abstinencia de la nicotina.

Terapeuta:-¿Qué tal esta semana? [3a llamada].

Sujeto: -Bueno, pues más o menos como la anterior.

Terapeuta: - ¿Ha leído la unidad 3 de su manual? Sujeto: -Sí, sí, la he leído.

Terapeuta: -¿Y está haciendo los autorregistros?

Sujeto: -Los registros a veces no los hago.

Terapeuta: -Ya le expliqué la semana pasada la importancia de hacer a diario los registros.

Sujeto: -Sí, ya lo sé, pero me cuesta.

Terapeuta: -¿Cuánto ha fumado de media esta semana? 
Sujeto: -Pues, sobre 15.

Terapeuta: - ¿No ha pasado nunca de 15 ?

Sujeto: -Sí, algún día fumé 18, LM Light. Pero también estuve tres días sin fumar.

Terapeuta: - ¿Y cómo fue eso?

Sujeto: -Pues, después de leer las enfermedades que producía el tabaco, decidí dejarlo. Pero sólo aguanté tres días.

Terapeuta: -Es que todavía es pronto para dejar de fumar L. Piense que la semana pasada estaba fumando una media de 20 cigarrillos diarios. Debe procurar seguir las instrucciones que se le indican para cada semana y no tratar de avanzar demasiado rápido, pues ello puede provocar un retroceso.

Sujeto: -No, ahora ya me di cuenta.

Por otra parte, algunos fumadores que han realizado intentos previos de abandono del tabaco, a veces, incluso antes de haber dejado de fumar, ya están anticipando que, aunque consigan dejar de fumar, no van a ser capaces de mantenerse abstinentes, pues tienen la experiencia de fracasos anteriores. La siguiente llamada fue realizada en la cuarta semana (mes de noviembre) a un fumador que informa estar fumando una media de 6 cigarrillos diarios.

Terapeuta: $\quad$-...o sea, que lo lleva muy bien [4 ${ }^{a}$ llamada].

Sujeto: -Sí, yo creo que sí. Yo lo que temo es ahora en estas fechas navideñas. Ya sabe que siempre se bebe algo más de la cuenta, se sale más ...

Terapeuta: -Bueno, primero vamos a centrarnos en dejarlo.

Sujeto: -Sí, eso es cierto. Lo que ocurre es que ya dejé de fumar en una ocasión.

Terapeuta: -Entiendo, pero esta ocasión es distinta a la anterior. Por lo tanto, si le parece, primero vamos a conseguir dejar de fumar y después veremos como hacer para no volver a fumar. Por eso no se preocupe ahora. Lea la unidad 4 de su manual en la que se trata el tema de la caída/recaída y la próxima semana, que ya habrá dejado de fumar, abordaremos el tema.
Sujeto: -De acuerdo, intentaré hacerlo.

Como se ha comentado con anterioridad, este tratamiento aborda tanto la dependencia fisiológica, como la psicológica y social que crea el tabaco. Si se siguen las instrucciones semanalmente, a algunos fumadores les resulta extremadamente sencillo dejar de fumar, pues pierden su dependencia fisiológica muy rápidamente y en torno a la tercera semana ya están abstinentes, a veces casi sin darse cuenta y sin haberlo planificado. Sin embargo, puede ocurrir que esta pérdida de dependencia fisiológica tan rápida no vaya a la par de la pérdida de dependencia psicológica y/o social, y se produzca una discordancia entre su conducta (no fumar) y cómo se siguen viendo (como fumador/a), pues todavía existe dependencia psicológica. En estos casos, pueden utilizar la estrategia de tomar al pie de la letra lo comentado en el manual de tratamiento, en relación a que no se debe tratar de avanzar demasiado rápido pues esto puede llevar al fracaso, como justificación para volver a fumar. El siguiente caso es el de una fumadora que llevaba cinco días sin fumar y ante la pregunta acerca de si había dejado de fumar, responde a medias. Esta es una respuesta bastante frecuente, por ello es importante conocer cuál es su definición de no fumador/a.

Terapeuta:-¿Cómo le ha ido esta semana? [llamada realizada en la tercera semana de tratamiento].

Sujeto: -Pues, eso le quería contar, porque resulta que desde el miércoles no fumé y no sabía lo que tenía que hacer.

Terapeuta: - ¿Ha dejado de fumar?

Sujeto: -Bueno, a medias.

Terapeuta: -¿Como a medias?, ¿hoy ha fumado algún cigarrillo? 
Sujeto: -No, hoy no, ya le dije que desde el miércoles no fumé más.

Terapeuta: -Bueno, pues entonces ha dejado de fumar. ¡Enhorabuena!

Sujeto: -Gracias, pero es que estuve dudando todo el tiempo.

Terapeuta: -¿Qué duda tuvo?

Sujeto: -Pues resulta que el miércoles tenía mal la garganta, entonces ese día no fumé nada. Pero no sabía si estaba bien, o si estaba mal y tenía que volver a fumar. Porque, como todavía estoy en la tercera semana, y decía al principio del libro que no se debe saltar ninguna unidad, ni apurarse, porque puede haber fracaso, dije yo: «bueno, si tengo que fumar, pues fumo, vaya».

Terapeuta: -¿Cuánto estaba fumando y de qué marca?

Sujeto: -Peter Stuyvesant. Además, ese tabaco no me gusta.

Terapeuta: -¿Ultra Light?

Sujeto: -Sí, y sólo fumé el lunes y el martes. El martes fumé 4 y el lunes fumé 5 ó 6 .

Terapeuta: - $Y$ el miércoles ya no fumó.

Sujeto: -No.

Terapeuta: -Bueno, pues se terminó.

Sujeto: -Claro, pero tengo un poco de miedo a recaer.

Terapeuta: -No tiene porqué tener miedo. Con lo poquito que usted estaba fumando era el momento adecuado para dejarlo. Ahora lo importante es que se plantee la abstinencia día a día. Además debe leer la unidad 5.

Sujeto: -No, ya la leí, jeh!

Terapeuta: -Porque le puede ayudar a buscar estrategias para enfrentarse a situaciones que supongan un riesgo para usted. Además, se comentan algunas sensaciones que puede notar al dejar de fumar. Pero no se preocupe, lo va a llevar bien.

Sujeto: -¡Vale!, yo lo que quería saber era eso, porque como aún estaba en la tercera semana.

Terapeuta: -Cada fumador tiene su momento. Tiene que pensar que la marca que usted estaba fumando es muy baja y, además, fumaba sólo la mitad del cigarrillo. Por lo tanto, ya no tenía dependencia física.

Sujeto: -La mitad, sí.

Terapeuta: -Fumar 5 cigarrillos de una marca tan baja y, además, por la mitad, equivale en nicotina a uno de los que fumaba cuando empezó el tratamiento.

Sujeto: -Sí, no era nada, el cigarrillo era muy flojo y ya no sentía placer al fumar, y también tengo la garganta mala, o sea que...

Terapeuta: -Además, es ideal aprovechar para dejar de fumar cuando uno se encuentra mal, porque ya de por si apetece menos.

Sujeto: -¡Claro, sí!

Terapeuta: -Pues no se preocupe porque ha hecho lo correcto. Es normal que al principio tenga algo de miedo, porque es una situación nueva para usted, pero, a medida que pasen los días, se encontrará cada vez mejor. Además, el tener miedo no es malo, así también estará más alerta.

\section{Ganas de fumar}

Una vez que se ha logrado dejar de fumar, es habitual experimentar lo que se denomina impulsos/necesidad de fumar craving. Esto consiste en sentir un impulso o necesidad, en un momento dado, que no tiene que estar, necesariamente, relacionado con personas presentes o situaciones concretas, y que conlleva un fuerte deseo de fumar. Estos impulsos se deben a la repetición múltiple y continuada en el pasado de cientos de cigarrillos fumados, que han estado asociados tanto a situaciones internas como externas. En ocasiones, los fumadores tienen la expectativa de que, una vez que dejen de fumar, no se van a acordar más del tabaco ni les va apetecer, y se sorprenden cuando esto les ocurre. Por ello, es habitual que 
pregunten si se van a seguir acordando durante mucho tiempo. En este caso es importante aclararles que esto es normal en el proceso de abandono del tabaco.

Terapeuta: - ¿Lo lleva bien? [ex fumadora que lleva una semana sin fumar].

Sujeto: -Bien, bueno, es bastante difícil, jeh! Pero bien.

Terapeuta: - ¿Cada vez mejor?

Sujeto: -Sí, yo pensé, que quizás ahora, a estas alturas, fuera bastante más fácil, pero bueno estoy viendo que la cosa aún está bastante difícil. De todas formas, como mi marido está también dejándolo, pues yo casi tengo la obligación...

Terapeuta: -De dar ejemplo.

Sujeto: -Sí, entonces ya me obliga a, porque vamos, a veces, pecaría ¡eh!, de buena gana.

Terapeuta: -No se preocupe, a medida que vayan pasando los días se acordará cada vez menos y las ganas de fumar durarán menos tiempo.

Sujeto: -Y, ¿cuánto tiempo pueden durar aún esas ganas?

Terapeuta: -Depende de cada caso, pero unos días más. Lo importante es que tenga en cuenta que esto es normal que ocurra, piense que acaba de abandonar un hábito diario de muchos años. Conforme avancen los días, notará que cada vez se acuerda con menor frecuencia e intensidad. Piense que de momento sólo lleva una semana sin fumar y ha estado fumando 16 años ininterrumpidamente.

Sujeto: -Sí, bueno, es cierto; pues, muchísimas gracias.

\section{Creencia «al dejar de fumar me con-} vierto en otra persona distinta»

Una creencia de algunos fumadores es que al dejar de fumar cambia su carácter, se vuelven más ansiosos, nerviosos, irascibles, etc. Esto no es así, a menos que se haya dejado de fumar bruscamente y se sufra el síndrome de abstinencia de la nicotina, algo que se evita con este procedimiento pues la reducción es gradual. Sin embargo, puede ocurrir que hayan tenido experiencias previas de intentos de abandono del tabaco que les hayan provocado mucha ansiedad, o que otros fumadores les digan que cuando uno deja de fumar cambia el carácter. Esto puede predisponerles a prestar mayor atención a cualquier cambio que les ocurra, aunque se trate de algo puntual y, a veces, se utiliza como "excusa" para no dejar de fumar o, una vez que se ha dejado, volver a fumar. Por ello, en la unidad 5 del manual, se aclara que al dejar de fumar uno sigue siendo tal y como era antes. En todo caso, los cambios son para mejor.

Terapeuta:-¿Qué tal le ha ido esta semana? [llamada realizada en la tercera semana a una fumadora que estaba a punto de dejar de fumar].

Sujeto: -iMire!, ahora duermo mal y estoy muy vaga, que es algo raro en mí, que soy una persona muy activa.

Terapeuta: -Pero, jno se lo achaque todo al tabaco!..., posiblemente se trate de algo pasajero. Ahora está a punto de dejarlo y pronto empezará a notar mejoría física. No se preocupe, es muy probable que la próxima semana vea las cosas de otra manera.

Sujeto: - $A$ ver si es verdad! Porque es que ya me preocupa. Ya digo, ¡Dios mío!, ¿me volveré vaga?

Terapeuta: -No. Lo habitual es que tenga la sensación de que le sobra tiempo. El dejar de fumar no la va a convertir en otra persona distinta de la que es ahora.

Sujeto: -¡Espero que no!, pero yo pienso que es normal que uno se sienta un poco raro, el organismo necesita también un tiempo para acostumbrarse.

Terapeuta: -Sí, para adaptarse a la nueva situación, claro. Tiene que darle tiempo. Piense que llevaba muchos años fumando y era una conducta 
que tenía asociada a muchas situaciones de su vida cotidiana.

Sujeto: -Prácticamente a todas.

\section{Distinción entre caída y recaída}

En la unidad 4 del manual se comenta una de las creencias más arraigadas entre los ex fumadores. La mayoría creen que fumando un cigarrillo, una vez abstinentes, se harán de nuevo fumadores como antes. Esto no tendría mayor importancia si no fuese porque las creencias de las personas producen en ellas procesos atribucionales que les llevan a actuar en función de las mismas. Así, si esto ocurriese realmente, la persona interpretará todo lo que le ocurra en función de esta creencia, sin prestar atención a otros aspectos de la situación que puedan indicar lo contrario. De hecho, suele ocurrir que ese primer cigarrillo sabe fatal y no apetece otro. De no existir presión social, lo más probable es que no se volviera a probar otro. Por lo tanto, la caída es un acontecimiento puntual que no implica la recaída. Una persona que deja de fumar no debe volver a hacerlo, no debe aceptar cigarrillos y, si esto ocurriera, debe centrarse en las sensaciones de malestar que produce fumar ese cigarrillo y no pasar al siguiente. El que los fumadores conozcan esta distinción es importante, pues les ayuda en el caso de tener un consumo puntual.

Terapeuta: -¿Qué tal lo lleva V.? [sexta llamada a un fumador que había dejado de fumar en la cuarta semana].

Sujeto: -Regular, he fracasado.

Terapeuta: -¿Cómo que ha fracasado?

Sujeto: -Sí, porque el fin de semana fumé dos pitillos.
Terapeuta: -¿Sábado y domingo?

Sujeto: -No, sólo el sábado. El domingo no salgo.

Terapeuta: -Y, desde el sábado, ¿ha vuelto a fumar? [llamada realizada el miércoles].

Sujeto: -No.

Terapeuta:-Bueno, pues no se preocupe. Simplemente procure que eso no vuelva a ocurrir. Piense que ha sido un consumo puntual y lo importante es que se quede en eso. Vuelva a leer la unidad 4, en lo que concierne a la distinción entre caída y recaída, y piense en ese consumo como una experiencia de aprendizaje. Es decir, céntrese en qué es lo que le llevó en ese momento a fumar, para que en futuras situaciones similares no vuelva a suceder.

\section{Discusión}

Una de las principales limitaciones que se le achacan a las intervenciones psicológicas de autoayuda en general es la falta de adherencia a las mismas. En tabaquismo, diferentes estudios (p. ej., Gritz et al., 1988; Warnecke et al., 1989) han encontrado relación entre el nivel de lectura y/o uso de diferentes manuales de autoayuda y el porcentaje de abstinencia obtenido en los seguimientos. Asimismo, otras investigaciones ( $p$. ej., Davis et al., 1984) se quejan de no haber obtenido los resultados esperados, posiblemente debido a la incapacidad de promover una realización rigurosa de las estrategias contenidas en los manuales, pues no llega con proporcionar los materiales necesarios para dejar de fumar. Hay que asegurarse, también, de que se hace un uso adecuado de ellos.

Se ha comprobado que el contacto telefónico regular con los fumadores que utilizan materiales de autoayuda influye positivamente en los porcentajes de abstinencia obtenidos (Brown et al., 1992; Míguez et al., 2002; Míguez \& Becoña, 2008), bien porque se promueven 
unos mayores niveles de adherencia al contenido de los materiales escritos (Brown et al., 1992), bien porque el consejo personaliza la información de los materiales (Rimer, Orleans, Fleisher et al., 1994) o porque se proporciona refuerzo a los intentos de abandono del tabaco (Orleans et al., 1991). De hecho esto es lo que ha ocurrido en este grupo de tratamiento objeto de análisis, cuyos resultados de abstinencia fueron similares a los de un programa de intervención clínico (véase Míguez et al., 2002).

Asimismo, cuando se ha solicitado la valoración del programa de tratamiento, se ha observado, a través de los comentarios realizados por los propios participantes, que las llamadas proporcionan otras ventajas además de las comentadas anteriormente: en unos casos, el empuje y disciplina necesarios para llevar a cabo el tratamiento $y$, en otros, el apoyo social del que carecen. Algunos testimonios al respecto fueron los siguientes: «necesitaba a alguien que me dijera que sí podía lograrlo, porque no tenía apoyo de nadie»; "yo necesitaba un apoyo y fue lo que tuve, sino, nunca lo hubiese conseguido»; "la llamada te obliga a ponerte a ello»; "yo la cuarta semana me desmadré y si no hablara contigo, hubiera abandonado el programa y no llegaría a dejar de fumar. Es un contacto más directo que las cartas"; "las llamadas te fuerzan a hacerlo en el tiempo que se te manda, sino, lo prolongarías más. Así sabes que te van a llamary tienes que responder».

La finalidad de las llamadas telefónicas en los distintos estudios es diversa. Además de evaluar el estatus de fumar, también se han utilizado para conocer qué estrategias utilizan los participantes a lo largo del tratamiento y si leen, o no, el material de autoayuda (p. ej., Brown, Hunt y Owen, 1992). En el presente estudio, para seguir la evolución de los sujetos durante el tratamiento, y poder analizar su adherencia, en las llamadas telefónicas realizadas semanalmente se les preguntaba si habían realizado cada una de las tareas indicadas, cómo las habían llevado a cabo, y se indagaba acerca de posibles dificultades surgidas en la realización de las mismas. Cuando informaban sobre algún tipo de dificultad, se les explicaba cómo solventarla. El mayor número de dificultades se detectaron en la primera y segunda llamada, en relación a tareas concretas, y entre la cuarta y quinta llamada, en relación al momento de dejar de fumar y días posteriores.

En un programa de estas características, de las seis llamadas efectuadas, destacan dos por su importancia a nivel terapéutico. Así, la primera llamada resulta esencial para motivar a algunos fumadores a iniciar el tratamiento, puesto que, de no realizarse, un porcentaje de los sujetos no llegaría a empezarlo. Esto puede deberse a falta de decisión para comenzar, bien porque subestimen sus posibilidades $y$ se desanimen ante la mínima adversidad, bien porque tras una ausencia de su domicilio se les hayan acumulado las cartas con las instrucciones semanales, etc. El caso es que, por una causa o por otra, lo van posponiendo y nunca encuentran un momento oportuno para empezar. Ya en los años 80, Kanfer (1980) indicara que el rol del terapeuta dentro de la autoayuda es el de instigador y motivador para que el cliente empiece un programa de cambio. A su vez, se debe tener presente que si se consigue que empiecen el tratamiento, una vez comen- 
zado éste, resulta más difícil que se abandone, y una menor atrición conlleva implícitamente una mayor probabilidad de conseguir la abstinencia.

Por otra parte, hacia la cuarta semana, se ha observado que hay un porcentaje de fumadores que, llegado este momento, no consiguen descender más en su consumo y se estancan en una cantidad mínima de cigarrillos, sin atreverse a dar el último y definitivo paso: dejar de fumar. Éste es un aspecto que también se observa en el ámbito clínico. En este momento, la llamada sirve para darles ese pequeño empujón que necesitan, para transmitirles que se encuentran preparados para dejar de fumar, que no lo van a pasar mal y que tienen que decidir el día en que lo van a dejar. Además, como su consumo es mínimo, en comparación a lo que fumaban cuando empezaron el tratamiento y fuman una marca baja en nicotina, es habitual que en estos casos empiecen a plantearse un nuevo objetivo, que no siempre se hace explícito. Nos referimos a quedarse así, es decir, fumando un número reducido de cigarrillos, bajo la creencia que será posible mantenerse en una situación de fumar controlado. En estos casos se debería indagar si su meta, con respecto a la conducta de fumar, ha cambiado, pues puede que sea lo que dificulte el abandono.

Es de lo más frecuente, que en estudios publicados en relación a tratamientos que han logrado buenos resultados, los autores se limiten a enumerar las técnicas que se han utilizado, pero no informen de cómo se llevan a cabo ni las dificultades que en ocasiones surgen, lo cual dificulta la replicación de dicho tratamiento por parte de otros profesionales. Aspiramos a que cada vez más profesionales se sumen a combatir el tabaquismo. Puesto que son muchos los que en España utilizan este tratamiento, nos ha parecido de utilidad práctica mostrar algunas dificultades con las que se pueden encontrar y proporcionarles pautas de cómo solventarlas.

Cabe destacar que las dificultades comentadas a lo largo de este artículo no son exclusivas del tratamiento de autoayuda. Las únicas situaciones exclusivas de la autoayuda son el no comenzar el tratamiento, después de haberlo solicitado y recibido, y la lectura del manual. Las demás se pueden dar en el Programa para Dejar de Fumar independientemente del formato de aplicación que se utilice: clínico (individual y/o grupal) o autoayuda, y también en otros tratamientos que utilizan las mismas estrategias (p. ej., autorregistros). A su vez, en el caso de la intervención de autoayuda, se observa que la mayor parte de las dificultades parten de dos aspectos fundamentales: ausencia de una adecuada lectura del material y falta de conciencia de la trascendencia de cada una de las tareas indicadas a lo largo del tratamiento, es decir, en algunos casos se subestima la relevancia de determinadas tareas y, en consecuencia, no se llevan a cabo (Míguez \& Becoña, 2005). Por ello, es muy importante insistir en la finalidad de las mismas, aspecto que a nivel clínico se hace en las sesiones presenciales que tienen lugar cada semana.

Consideramos que, para detectar posibles problemas o formas incorrectas de llevar a cabo algunas de las tareas del tratamiento, es importante no quedarse sólo en la pregunta «¿ha hecho ...?», si no que es necesario ir más 
allá, e indagar acerca de cómo lo ha hecho. Así, si estamos preguntando por el control de estímulos, no conformarse con que nos respondan a si han elegido tres situaciones en las que no van a fumar, a continuación es necesario saber si dicha tarea la han cumplido todos los días y si fumaban habitualmente en las situaciones elegidas (Míguez \& Becoña, 2010).

Por otra parte, tanto el terapeuta como el fumador deben tener en cuenta que las tareas que se indican en este programa de tratamiento son acumulativas. Es decir, en el supuesto de que en una semana no se cumpla alguna de las tareas (p. ej., retrasar 15 minutos el cigarrillo después de la comida), con respecto a esta tarea no se pasará a lo indicado para la siguiente semana (retrasar 30 minutos el cigarrillo después de la comida), hasta que se haya superado lo correspondiente a la semana previa.

Quedan todavía cuestiones por analizar en esta modalidad de intervención. Una de ellas hace referencia a si la participación en un contexto de autoayuda requiere más automotivación, puesto que lo habitual es que no implique contacto personal con el terapeuta (Sussman et al., 1994). En este caso, el fumador tiene que convertirse en su propio terapeuta. Futuras investigaciones en este tipo de programas debieran dirigirse a definir las características de los fumadores para los cuales resultan más convenientes. También se necesitan esfuerzos encaminados a atraer a los fumadores a usar este tipo de abordaje y a solventar el problema de la pérdida de adherencia a las tareas del tratamiento, puesto que muchas intervenciones terapéuticas pierden eficacia por la falta de adherencia a las mismas. Esto ocurre sobre todo en los procesos que implican cambios de conducta que afectan a los hábitos de la vida cotidiana, como ocurre en las conductas adictivas en general (Wiggers et al., 2006). Teniendo en cuenta todo lo anterior, el mantenimiento de la adherencia a los tratamientos debiera plantearse como un objetivo terapéutico más.

\section{Referencias}

American Lung Association (1984). Freedom from smoking in 20 days. Washington, DC: Author.

American Lung Association (1986). A lifetime of freedom from smoking: $A$ maintenance program for ex-smokers. New York, NY: Author.

Becoña, E. (1993). Programa para deixar de fumar. Santiago de Compostela: Servicio de Publicacións da Universidade de Santiago de Compostela.

Becoña, E. (2007). Programa para dejar de fumar. Vigo: Nova Galicia Edicións.

Brown, S. L., Hunt, G. \& Owen, N. (1992). The effect of adding telephone contact to selfinstructional smoking-cessation materials. Behaviour Change, 9, 216-222.

Brown, S. L. \& Owen, N. (1992). Self-help smoking cessation materials. Australian Journal of Public Health, 16, 188-191.

Cummings, K. M., Emont, S. L., Jaen, C. \& Sciandra, R. (1988). Format and quitting instructions as factors influencing the impact of a self-administered quit smoking program. Health Education Quarterly, 15, 199-216.

Curry, S. J. (1993). Self-help interventions for smoking cessation. Journal of Consulting and Clinical Psychology, 61, 790-803.

Curry, S. J., Ludman, E. J. \& McClure, J. (2003). Self-administered treatment for smoking cessation. Journal of Clinical Psychology, 59, 305-319. 
Danaher, B. G. \& Lichtenstein, E. (1978) Become and ex-smoker. Englewood Cliffs, NJ, Prentice Hall.

Davis, A. L., Faust, R. \& Ordentlich, M. (1984). Selfhelp smoking cessation and maintenance programs: A comparative study with 12-month follow-up by the American Lung Association. American Journal of Public Health, 74, 1212-1217.

Glasgow, R. E., Schafer, L. \& O'Neill, H. K. (1981). Self-help books and amount of therapist contact in smoking cessation programs. Journal ofConsulting and Clinical Psychology, 49, 659-667.

Glynn, T. J., Boyd, G. M. \& Gruman, J. C. (1990). Essential elements of self-help/minimal intervention strategies for smoking cessation. Health Education Quarterly, 17, 329-345.

Gritz, E. R., Marcus, A. C., Berman, B. A., Read, L. L., Kanim, L. E. \& Reeder, S.J. (1988). Evaluation of a worksite self-help smoking cessation program for registered nurses. American Journal of Health Promotion, 3, 26-35.

Kanfer, F. H. (1980). Self-management methods. En F.H. Kanfer \& A.P. Goldstein (Eds.), Helping People Change. New York, Pergamon Press. op. 309-355

Lancaster, T., Stead, L. F. (2009). Self-help interventions for smoking cessation. (Cochrane Review). En The Cochrane Library, 2. Oxford: Update Software.

Lando, H. A. (1993). Formal Quit Smoking treatments. En C. T. Orleans \& J. Slade. Nicotine addiction principles and management (pp. 221-244) New York, NY: Oxford University Press.

Lenert, L., Muñoz, R. F., Stoddard, J., Delucchi, K., Bansod, A., Skoczen, S. \& Pérez-Stable, E. J. (2003).Design and pilot evaluation of an Internet smoking cessation program. Journal of American Medical Information Association, 10, 16-20.

Lichtenstein, E. (1982). The smoking problem: A behavioral perspective. Journal of
Consulting and Clinical Psychology, 50, 804-819.

Mains,J.A.\&Scogin,F.R.(2003).Theeffectiveness of self-administered treatments: a practicefriendly review of the research. Journal of Clinical Psychology, 59, 237-246.

McMorrow, M. J., Foxx, R. M. (1983). Nicotine's role in smoking: An analysis of nicotine regulation. Psychological Bulletin, 93, 302327.

McMorrow, M. J., Foxx, R. M. (1985). Cigarette brand switching: Relating assessment strategies to the critical issues. Psychological Bulletin, 98, 139-159.

Míguez,M.C.\&Becoña,E.(2003).Laintervención de autoayuda por correo en el tratamiento de fumadores. Revista de Psicopatología y Psicología Clínica, 8, 109-126.

Míguez, M. C. \& Becoña, E. (2005). Dejar de fumar mediante un procedimiento de autoayuda: análisis del incumplimiento de tareas. Psicología Conductual, 13, 243-253.

Míguez, M. C. \& Becoña, E. (2008). Evaluating the effectiveness of a single telephone contact as an adjunct to a self-help intervention for smoking cessation in a randomized controlled trial. Nicotine and Tobacco Research, 10, 129-135.

Míguez, M. C. \& Becoña, E. (2010). El proceso de dejar de fumar, En E. Becoña (coord.), Dependencia del tabaco. Manual de casos clínicos (pp. 59-80). Madrid: Sociedad Española de Psicología Clínica, Legal y Forense.

Míguez, M. C., Vázquez, F. L. \& Becoña, E. (2000). Realización de las tareas en un tratamiento para dejar de fumar y sus repercusiones clínicas. Revista de Psicología Contemporanea, 7, 32-35

Míguez, M. C., Vázquez, F. L. \& Becoña, E. (2002). Effectiveness of telephone as an adjunct to a self-help program for smoking cessation: A randomized controlled trial in Spanish smokers. Addictive Behaviors, 7, 139-144. 
Orleans, C. T., Schoenbach, V. J., Wagner, E. H., Quade, D., Salmon, M. A., Pearson, D. C.,... Kaplan, B. H. (1991). Self-help quit smoking interventions: Effects of self-help materials, social support instructions and telephone counseling. Journal of Consulting and Clinical Psychology, 59, 439-448.

Owen, N., Ewins, A. L. \& Lee, C. (1989). Smoking cessation by mail: A comparison of standard and personalized correspondence course formats. Addictive Behaviors, 14, 355-363.

Rimer, B. K., Orleans, C. T., Fleisher, L., Cristinzio, S., Resch, N., Telepchak, J. \& Keintz, M. K. (1994). Does tailoring matter?The impact of a tailored guide on ratings and short-term smokingrelated outcomes for older smokers. Health Education Research, 9, 69-84.

Schwartz, J. L. (1987). Review and evaluation of smoking cessation methods. The United States and Canada, 1978-1985. Rockville, MD:U.S. Departamnet of Health and Human Services. National Institutes of Health.

Sussman, S., Dent, C. W., Wang, E., Cruz, N. T. B., Stanford, D. \& Johnson, C.A. (1994). Participants and nonparticipants of a mass media self-help smoking cessation program. Addictive Behaviors, 19, 643-654.
U.S.D.H.H.S. (1988). The health consecuences of smoking: Nicotine addiction. A Report of the Surgeon General. Rockville, MD: U.S. Department of Health Human Services, Office on Smoking and Health.

Warnecke, R. B., Langenberg, P., Gruder, C. L., Flay, B. R., Phil, D. \& Jason, L. A. (1989). Factors in smoking cessation among participants in a televised intervention. Preventive Medicine, 18, 833-846.

Wiggers, L. C., Smets, E. M., Oort, F. J., StormVerloot, M. N., Vermeulen, H., Van Loenen, L. B.,... Legemate, D. A. (2006). Adherence to nicotine replacement patch therapy in cardiovascular patients. International Journal of Behavioral Medicine, 13, 79-88.

World Health Organization (2008). WHO report on the global tobacco epidemic, 2008 Author. 